\title{
Protoplast Formation and Regeneration of Clostridium acetobutylicum Strain N1-4080
}

\author{
By GILLES REYSSET,* JACQUES HUBERT, LAURENCE PODVIN AND \\ MADELEINE SEBALD \\ Unité des Anaérobies, Institut Pasteur, 25 rue du Dr Roux, 75724 Paris Cedex 15, France
}

(Received 20 January 1987; revised 27 March 1987)

\begin{abstract}
A method for the production of protoplasts of Clostridium acetobutylicum strain N1-4080 utilizing lysozyme and penicillin $\mathrm{G}$ was optimized to yield about $100 \%$ protoplasts. Treatment of $10^{9}$ cells left fewer than $10^{2}$ that were viable and osmo-resistant. With a mutant strain deficient in autolytic activity, about $1 \%$ of the protoplasts regenerated walled cells, whereas most gave rise to stable L-form colonies. Addition of sodium polyanethole sulphonate to the medium improved the regeneration frequency by at least a factor of 10 , probably by somehow inhibiting the residual autolytic activity of the strain.
\end{abstract}

\section{INTRODUCTION}

Improvement in regeneration of protoplasts is a priority for developing the genetics of solvent-producing clostridia. Pioneering work on the preparation and regeneration of protoplasts of saccharolytic clostridia of industrial interest has been done during this decade in Clostridium acetobutylicum (Allcock et al., 1982), 'Clostridium saccharoperbutylacetonicum' (Yoshino et al., 1984) and Clostridium pasteurianum (Minton \& Morris, 1983). For $C$. acetobutylicum further reports described PEG-mediated transformation (Lin \& Blaschek, 1984) or fusion (Jones et al., 1985) of the protoplasts but the regeneration frequencies, if significant, were low. Moreover, we could not reproduce these results by using reference or laboratory strains.

We decided, therefore, to develop protoplast regeneration in a strain (N1-4) of Clostridium producing acetone and butanol that was isolated and described as a new species, ' $C$. saccharoperbutylacetonicum', by Hongo (1960). Because this species name has not been validly published, we include it temporarily in $C$. acetobutylicum. This strain was used for the following reasons: (i) unlike other strains of $C$. acetobutylicum, it produces butanol over a wide $\mathrm{pH}$ range (Hongo 1960); (ii) the results of Yoshino et al. (1984) indicated protoplast regeneration in this strain; (iii) attempts at protoplast regeneration in C. acetobutylicum led us to think that the lack of regeneration had something to do with endogenous autolytic activity. However, we knew little about the autolytic enzymes of most strains of $C$. acetobutylicum whereas more valuable data had been published on the autolysin of strain N1-4 (Yoshino et al. (1982). In addition, strain N1-4 has unusual and potentially important properties, the so-called 'sucrose-induced' autolysis and protoplast-like formation (Ogata et al., 1975).

\section{METHODS}

Strains. C. acetobutylicum strain N1-4080 was used as a reference strain. This strain is a derivative of strain N1-4 (Hongo, 1960) carrying two mutations: a spontaneous rifampicin resistance, and an auxotrophy for proline which was obtained by EMS mutagenesis (this work). The strain N1-4081 is an autolysin-deficient mutant of strain N1-4080 (this work).

Abbreviation: SPS, sodium polyanethole sulphonate. 
Media. TYA medium (Ogata \& Hongo, 1973) was used for routine cell growth and in experiments to measure cell numbers. Two other media derived from TYA medium, T69 and T68, were used (see below). T69 medium contained $\left(\mathrm{g} \mathrm{l}^{-1}\right): \mathrm{KH}_{2} \mathrm{PO}_{4}, 0.5$; ammonium acetate, $2 ; \mathrm{MgSO}_{4} \cdot 7 \mathrm{H}_{2} \mathrm{O}, 0.3 ; \mathrm{FeSO}_{4} .7 \mathrm{H}_{2} \mathrm{O}, 0.01$; Yeast extract (Difco), 1 ; Casamino acids (Difco), 0.5; Bacto-tryptone (Difco), 0.5; cysteine. $\mathrm{HCl}, 0.5$. Synthetic T68 medium had the same composition, but it lacked yeast extract, Casamino acids and Bacto-tryptone, and was supplemented with biotin, thiamin and $p$-aminobenzoic acid, each at $1 \mathrm{mg} \mathrm{l}^{-1}$. In all cases the $\mathrm{pH}$ was adjusted to 6.5 with $\mathrm{NaOH}$, and glucose was added aseptically to a final concentration of $1 \%(\mathrm{w} / \mathrm{v})$. Proline was added to the T68 synthetic medium at $50 \mu \mathrm{g} \mathrm{ml}^{-1}$. For plating, agar (Difco) at $1.8 \%,(\mathrm{w} / \mathrm{v})$ was added to the media.

Media derived from T69 and T68 were used for protoplast formation (see below) and regeneration. The solid regeneration media (T68C and T69C) were T68 and T69 basal media supplemented with $0.3 \mathrm{M}$-sucrose, $1 \mathrm{mM}$ $\mathrm{CaCl}_{2}, 0.5 \%(\mathrm{w} / \mathrm{v}) \mathrm{BSA}$ and $2.5 \%(\mathrm{w} / \mathrm{v})$ agar (Difco). T69X was T69C with $0.25 \mathrm{M}$-xylose instead of $0.3 \mathrm{M}$-sucrose. In certain experiments sodium polyanethole sulphonate (SPS) $\left(0 \cdot 1\right.$ to $\left.1 \mathrm{mg} \mathrm{ml}^{-1}\right)$ was added.

All media and supplements were pre-reduced and anaerobically sterilized, except for lysozyme, BSA and SPS solutions, which were sterilized by filtration.

General conditions. All manipulations were done in an anaerobic chamber (Celster Isotechnic) with an atmosphere of $\mathrm{N}_{2} / \mathrm{CO}_{2} / \mathrm{H}_{2}\left(90: 5: 5\right.$, by vol.). Cultures were incubated in this chamber at $35^{\circ} \mathrm{C}$.

Mutagenesis. Mid-exponential phase cells were centrifuged and concentrated 10 times in T68 medium without glucose; EMS $(2 \% \mathrm{v} / \mathrm{v})$ was then added and the mixture was incubated for various times $(0$ to $60 \mathrm{~min})$. Samples were washed on filters ( $0.45 \mu \mathrm{m}$ pore size; Millipore) with T68 medium; cells were recovered, resuspended in the same medium and counted on TYA medium. For further treatments cell suspensions with a survival rate of $1 \%$ were used. Auxotrophic mutants were selected by the replica plating technique after overnight treatment with penicillin (1000 units $\mathrm{ml}^{-1}$ ) in T68 medium.

Protoplast formation and regeneration. Cells were grown in $\mathrm{T} 68$ or $\mathrm{T} 69$ media to mid-exponential phase (about $1 \times 10^{8}$ cells $\mathrm{ml}^{-1}$ ). Cultures were then adjusted with preweighed solid sterilized sucrose to $0.6 \mathrm{M}$, and $\mathrm{CaCl}_{2}$ was added to $1 \mathrm{mM}$ (final concentration). Protoplasts were obtained by adding lysozyme $\left(100 \mu \mathrm{g} \mathrm{ml}^{-1}\right)$, and penicillin $\mathrm{G}$ $\left(20 \mu \mathrm{g} \mathrm{ml}^{-1}\right)$, and incubating at $34^{\circ} \mathrm{C}$ for $60 \mathrm{~min}$. The protoplasts were recovered by centrifugation at $3000 \mathrm{~g}$ for 15 min at room temperature, washed twice with medium T68 or T69 containing $0.6 \mathrm{M}$ sucrose, $0.5 \% \mathrm{BSA}$ and $1 \mathrm{mM}-$ $\mathrm{CaCl}_{2}$, and resuspended in the same medium at $1 / 10$ of the initial volume. At this point, protoplasts were counted in a phase-contrast microscope using a Petroff-Hausser chamber. The protoplasts were also diluted in T68C or T69C medium, and plated on the corresponding solid regeneration media. Regenerants and L-form colonies were counted after 6 to $9 \mathrm{~d}$ incubation.

Differential counting of both forms was easy because the walled cells formed larger, brown colonies. Osmoresistant cells were diluted in hypotonic medium $\mathrm{T} 68$ or $\mathrm{T} 69$, and plated onto $\mathrm{T} 68 \mathrm{C}$ or $\mathrm{T} 69 \mathrm{C}$ medium respectively. The percentage regeneration frequency was calculated according to the formula $100 \times(b-c) / a$ where $a$ is the number of colonies counted before any lytic treatment (or protoplasts counted in a Petroff-Hausser chamber), $b$ the number of regenerant colonies and $c$ the number of osmo-resistant cells.

Preparation of cell walls. Cell walls of strain N1-4080 were prepared as by Ogata et al. (1974).

Assay of lytic activity. This was done by measuring the decrease in turbidity of a cell wall suspension. The reaction mixture contained $0.8 \mathrm{ml}$ cell wall preparation in $100 \mathrm{~mm}$-sodium acetate buffer, $\mathrm{pH} 4 \cdot 5\left(\mathrm{OD}_{660} 0 \cdot 15\right)$, and $0.2 \mathrm{mi}$ culture filtrate of growing cells, concentrated 10 times with $10 \%(\mathrm{w} / \mathrm{v}) \mathrm{PEG}$ in $67 \mathrm{mM}$-potassium phosphate buffer, pH 6.5. Lytic activity is expressed as Units (U): $1 \mathrm{U}$ is equivalent to a decrease in $\mathrm{OD}_{660}$ of $0.001 \mathrm{~min}^{-1}$.

\section{RESULTS}

\section{Formation of protoplasts}

C. acetobutylicum strain N1-4 autolyses in media containing 0.3 to $0.6 \mathrm{M}$ sucrose, the rodshaped cells being converted into autoplasts (Ogata et al., 1975). Autoplast formation was attributed to a specific autolysin, identified as a $N$-acetylmuramidase (Yoshino et al. 1982), and induced by the plasmolysing action of sucrose.

We showed that the efficiency of autoplast formation was related to the growth stage of the bacteria and reached a maximum at the end of the exponential phase with an efficiency of $99 \%$ (Table 1). Nevertheless, about $1 \%$ of the vegetative cells did not autolyse. The autoplasts were used for further experiments, but we could not regenerate them by the method of Yoshino et al. (1984), although Heefner et al. (1984) found that $C$. perfringens autoplasts were more suitable than protoplasts for regeneration. In order to decrease the number of residual osmo-resistant cells (see below), protoplasts were formed in $0.6 \mathrm{M}$-sucrose in the presence of lysozyme and/or penicillin. The protocol, which gave a high efficiency of protoplast formation, is outlined in Methods. 
Table 1. Influence of growth stage on autoplast formation of strain N1-4080

Strain N1-4080 was grown in TYA medium. At different stages of growth, $5 \mathrm{ml}$ of the culture was adjusted with preweighed solid sterilized sucrose to $0.6 \mathrm{M}$ and incubated at $35^{\circ} \mathrm{C}$ for $60 \mathrm{~min}$. Vegetative cells and autoplasts were then counted in a phase-contrast microscope using a Petroff-Hausser chamber.

\begin{tabular}{|c|c|c|c|c|}
\hline \multirow[b]{2}{*}{$\begin{array}{c}\text { OD } \\
\text { (Klett units) }\end{array}$} & \multicolumn{2}{|c|}{ Vegetative cells } & \multicolumn{2}{|c|}{ Autoplasts } \\
\hline & No. $\mathrm{ml}^{-1}$ & $\begin{array}{c}\text { Percentage of } \\
\text { total count }\end{array}$ & No. $\mathrm{ml}^{-1}$ & $\begin{array}{l}\text { Percentage of } \\
\text { total count }\end{array}$ \\
\hline 40 & $5 \cdot 1 \times 10^{7}$ & 99.8 & $1 \times 10^{5}$ & $0 \cdot 2$ \\
\hline 60 & $1 \times 10^{8}$ & 99.5 & $5 \times 10^{5}$ & 0.5 \\
\hline 87 & $6.25 \times 10^{6}$ & $2 \cdot 8$ & $2.1 \times 10^{8}$ & $97 \cdot 2$ \\
\hline 120 & $2.5 \times 10^{6}$ & 0.8 & $2.6 \times 10^{8}$ & $99 \cdot 2$ \\
\hline 190 & $6 \times 10^{7}$ & 6 & $6.2 \times 10^{8}$ & 94 \\
\hline
\end{tabular}

Table 2. Regeneration frequency of strains N1-4080 and N1-4081

Protoplasts, osmo-resistant cells, L-forms, regenerant colonies and percentage regeneration were determined according to Methods. Values in parentheses are the regeneration frequencies given as a percentage of the total number of protoplasts diluted. Results shown represent means of at least three separate experiments.

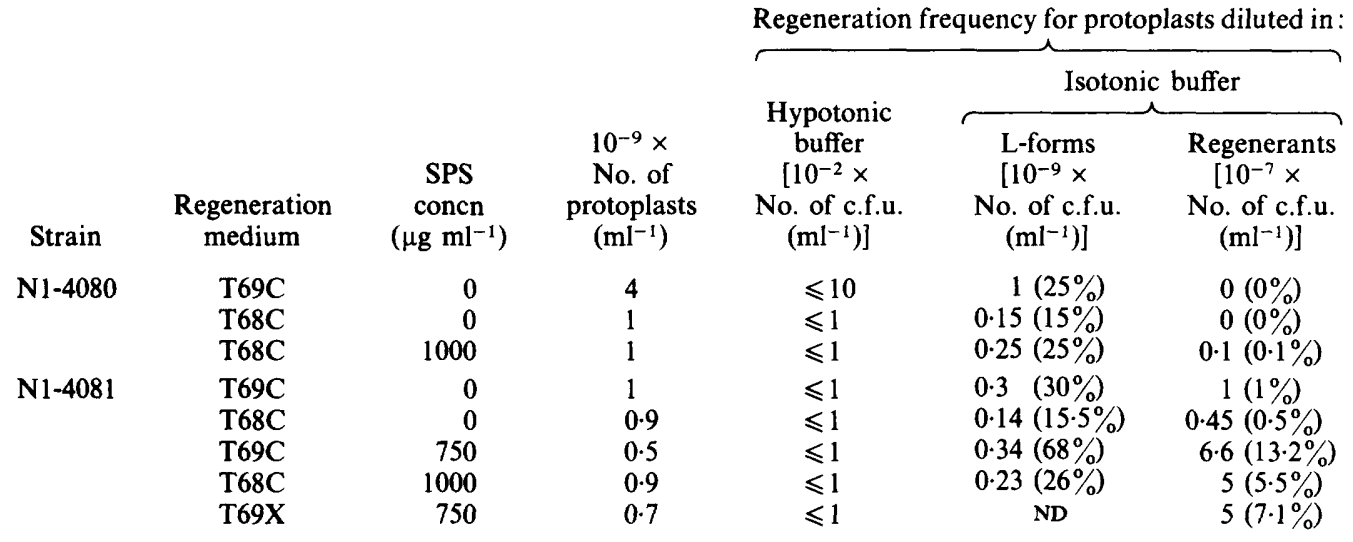

ND, Not done: on T69X L-form colonies were minute and counting was not possible.

A comparison between the number of viable cells counted before protoplast formation and protoplasts counted under the phase-contrast microscope (Petroff-Hausser chamber) showed that protoplast formation was near $100 \%$ under our experimental conditions, or even more $(120$ to $130 \%$ ), probably because some individual cells yielded two protoplasts. Usually, fewer than $10^{2}$ osmo-resistant cells $\mathrm{ml}^{-1}$ were found in a protoplast preparation from about $10^{9} \mathrm{cells} \mathrm{ml}^{-1}$ (Table 2).

Protoplasts could be obtained without lysozyme or penicillin G, but under these conditions the number of osmo-resistant cells occasionally increased. Since the protoplasting procedure was more efficient with early exponential phase cells, further experiments were done with cells from this growth phase, protoplasts being obtained by simultaneous treatment with lysozyme $(100 \mu \mathrm{g}$ $\left.\mathrm{ml}^{-1}\right)$ and penicilline $\mathrm{G}\left(20 \mu \mathrm{g} \mathrm{ml}^{-1}\right)$ for $1 \mathrm{~h}$ at $34^{\circ} \mathrm{C}$.

\section{Regeneration of C. acetobutylicum (strain N1-4080) protoplasts}

Yoshino et al. (1984) defined the regeneration conditions for $C$. acetobutylicum strain N1-4. Frequencies were $0.1 \%$ for protoplasts obtained with lysozyme and $1 \%$ for protoplasts obtained with phage HM7 $\mathrm{N}$-acetylmuramyl-L-alanine amidase (Hongo et al., 1974). The protoplasts were able to regenerate when PEG $4000(10 \%, w / v)$ was used as an osmostabilizer in a modified TYA medium. Unfortunately, when we used lysozyme, we were unable to reproduce their 
results. Nevertheless, starting with TYA basal medium, we developed a regeneration medium by systematically varying the concentrations of agar, glucose, sucrose, $\mathrm{Mg}^{2+}, \mathrm{Ca}^{2+}$, Casamino acids, yeast extract, bacto-tryptone and BSA. Finally, we developed media (see Methods) which gave rise to stable L-form colonies with yields of 10 to $35 \%$ of the N1-4080 protoplasts (Table 2). Unreproducible regeneration to walled cells was obtained in some experiments, but the frequency was never higher than $0.01 \%$. None of the following attempts to increase regeneration of protoplasts was successful: addition of autoclaved cells; treatment with $\mathrm{N}$-acetylglucosamine, D-alanine, D-glutamate or gelatin; spreading protoplasts on nitrocellulose filters $(0.45 \mu \mathrm{m}$ pore size; Millipore) overlaid on solid regeneration media, or modification of the osmostabilizer or the incubation temperature.

Preliminary results suggested a strong inhibition of L-form colonies and regenerants by any residual osmo-resistant cells. These observations were similar to those of De Castro-Costa \& Landman (1977) in Bacillus subtilis, and to those of Smith (1985) and Wirth et al. (1986) in Streptococcus faecalis. Moreover, some of our results suggested an inhibition of regeneration of walled cell colonies by L-form colonies. A diffusible autolysin produced either by rare osmoresistant cells or by $\mathrm{L}$-form colonies seemed to inhibit cell wall synthesis of regenerating protoplasts. We failed to overcome this difficulty by addition of gelatin or proteolytic enzymes to the regeneration media (cf. De Castro-Costa \& Landman, 1977). Moreover, gelatin at high concentration strongly inhibited the growth of our strain, as already observed in $C$. perfringens (Stal \& Blascheck, 1985) and C. pasteurianum (Minton \& Morris, 1983).

\section{Autolysin deficient mutant of $C$. acetobutylicum}

To increase the regeneration frequency of N1-4080 protoplasts, we decided to isolate mutant strains that were affected in autolytic activity, or were less sensitive to their autolysin. Such mutants were selected after EMS mutagenesis (see Methods) by their resistance to 'sucroseinduced' autoplast formation. This was done by seven alternative passages in TYA isotonic medium ( $0.6 \mathrm{M}$-sucrose) and TYA hypotonic medium. After re-isolation on TYA agar plates, a clone (N1-4081) was retained. It had the following properties: (i) it was unable to produce any autoplasts in $0.6 \mathrm{M}$-sucrose medium after $1 \mathrm{~h}$ at $34^{\circ} \mathrm{C}$; (ii) a high frequency of protoplast formation (near $100 \%$ ) was still obtained after a standard lysozyme and penicillin treatment; (iii) about $1 \%$ of protoplasts were able to regenerate, but the strain still produced L-form colonies on sucrose regeneration medium (Table 2).

In vitro activities of the N1-4080 and N1-4081 autolysins were determined as described in Methods, using filtrates of exponential-phase cultures as a source of enzyme: strain N1-4081 had only $30 \%$ of the autolytic activity shown by strain $\mathrm{N} 1-4080\left(0.2 \mathrm{U} \mathrm{ml}^{-1}\right.$ and $0.68 \mathrm{U} \mathrm{ml}^{-1}$, respectively). Mutant N1-4081 is thus partially affected in autolysin production.

\section{Effect of SPS on protoplast regeneration}

We speculate that poor regeneration obtained with strain N1-4081 could be due to residual autolytic activity, and thus sought a suitable autolysin inhibitor. SPS is a polyelectrolyte capable of inhibiting the spontaneous degradation of staphylococcal walls (Ginsberg \& Sela, 1976). It can also induce in staphylococci a suppression of the activity of different wall autolysins, and inhibit lysostaphin-induced wall disintegration of isolated cell walls devoid of endogenous autolysins (Wecke et al., 1986). These authors postulated an interaction of SPS with the cell wall itself (Wecke et al., 1986). Since SPS up to $1 \mathrm{mg} \mathrm{ml}^{-1}$ was not inhibitory for growth of strain N1-4080, we looked for inhibition of autoplast and protoplast formation in $0.6 \mathrm{M}$-sucrose media by various concentrations of SPS. As shown in Table 3, SPS inhibited autoplast and protoplast formation at a concentration as low as $100 \mu \mathrm{g} \mathrm{ml}^{-1}$, and strong inhibition occurred regularly at concentrations $\geqslant 500 \mu \mathrm{g} \mathrm{ml}^{-1}$. SPS also inhibited protoplast formation by lysozyme in strain N1-4081 (Table 3).

To test the efficiency of SPS on protoplast regeneration of strains N1-4080 and N1-4081, protoplasts were prepared in the absence of SPS as described in Methods and plated on T68C regeneration medium containing SPS at various concentrations up to $1 \mathrm{mg} \mathrm{ml}^{-1}$. The optimum concentration of SPS required was directly related to the total protein concentration in the 
Table 3. Formation of protoplasts and autoplasts in the presence of SPS Late exponential phase cells $\left(2.5 \times 10^{8} \mathrm{ml}^{-1}\right)$ (for autoplast formation) or early exponential phase cells
$\left(1 \times 10^{8} \mathrm{ml}^{-1}\right)$ (for protoplast formation) were adjusted to $0.6 \mathrm{M}$-sucrose in the absence (autoplasts) or
presence (protoplasts) of $100 \mu \mathrm{g}$ lysozyme $\mathrm{ml}^{-1}$ and various concentrations of SPS. The formation of
autoplasts or protoplasts was determined by microscopy after incubation for $1 \mathrm{~h}$ at $34^{\circ} \mathrm{C}$.

$\begin{array}{cccc}\begin{array}{c}\text { Autoplast } \\ \text { formation } \\ (\%)\end{array} & \begin{array}{c}\text { Protoplast } \\ \text { formation } \\ \left(\mu \mathrm{g} \mathrm{ml}^{-1}\right)\end{array} & \overbrace{\begin{array}{c}\text { Protoplast } \\ \text { formation } \\ (\%)\end{array}}^{\text {Strain N1-4081 }} \\ 0 & 95 & 90 & 100 \\ 100 & 30 & 5 & 0 \\ 500 & \leqslant 10 & <5 & 0 \\ 1000 & <5 & <5 & 0 \\ 2000 & <5 & <5 & 0\end{array}$

regeneration media since SPS precipitated BSA. At $0 \cdot 5 \%$ BSA, the optimum concentration of SPS was $750 \mu \mathrm{g} \mathrm{ml}^{-1}$. With lower concentrations of BSA, lower concentrations of SPS could be used, but regeneration did not occur at $<0.25 \%$ BSA. For both strains, additions of SPS increased the regeneration frequency by at least a factor of 10 (Table 2). Another significant effect of adding SPS to regeneration media was observed when we compared the numbers of colonies of walled cells and colonies of $\mathrm{L}$-forms recovered from protoplast suspensions at low dilutions $\left(\leqslant 10^{-3}\right)$ and high dilutions $\left(\geqslant 10^{-4}\right)$ in the presence or absence of SPS. L-form colonies predominated at low dilutions in the absence of SPS. This was particularly true for the lytic deficient mutant N1-4081.

\section{Protoplast regeneration with other osmostabilizers}

Xylose $(0.25 \mathrm{M})$ was an alternative to sucrose as an osmostabilizer in regeneration media. In media containing xylose, regeneration was more rapid ( 4 to $6 \mathrm{~d}$ ), while at the same time growth of $\mathrm{L}$-form colonies was inhibited. This may be related to different production kinetics of autolysin, because protoplasts do not form in liquid media containing $0.25 \mathrm{M}$-xylose. Regeneration frequencies were similar in sucrose and xylose (Table 2).

\section{DISCUSSION}

Protoplast formation and regeneration were achieved at a suitable frequency in $C$. acetobutylicum by using the lytic deficient mutant N1-4081, and by adding the autolysis inhibitor SPS as soon as protoplast formation was completed. A fundamental requisite for protoplast regeneration appeared to be a very efficient protoplast formation leaving no viable osmoresistant cells behind: hence the advantage of using lysozyme and penicillin together for protoplast formation.

At present it appears reasonable to assume that SPS inhibits the autolytic enzyme either directly or more probably by indirect action on its target site the cell wall, in particular the teichoic acids (Wecke et al., 1986). A study of the effect of other autolysin inhibitors on $C$. acetobutylicum protoplast regeneration should also be fruitful. Our best regeneration media contained relatively low concentrations of divalent cations ( $1 \mathrm{~mm}$ each of $\mathrm{Ca}^{2+}$ and $\mathrm{Mg}^{2+}$ ), in contrast to most of the regeneration media previously described. This low concentration of divalent cations is near to the $\mathrm{CaCl}_{2}$ concentration ( $5 \mathrm{mM}$ ) that antagonizes the lytic action of monovalent cations such as $\mathrm{Na}^{+}$(Ogata \& Hongo, 1973), present in traces in our media. Regeneration was more rapid on media containing $0 \cdot 25 \mathrm{M}$-xylose as osmostabilizer instead of $0 \cdot 3$ $\mathrm{M}$-sucrose, perhaps because xylose inhibited the formation of $\mathrm{L}$-form colonies, thereby decreasing residual autolytic activity. Finally, in our procedure, except for a few additives, the same basal medium was used for every step. With $C$. acetobutylicum any change of medium generally leads to cell lysis (G. Reysset, unpublished). 
To what extent our results, especially the use of SPS, can be applied to protoplast regeneration in other clostridia that do not regenerate has yet to be determined.

We thank Dr M. Hongo for his gift of strain N1-4. This investigation was supported by research funds from Institut Français du Pétrole, and CNRS-PIRSEM grants no. 3060 and 3227. L.P. was the recipient of a fellowship from ANRT/Sucrerie d'Attin (Convention CIFRE).

\section{REFERENCES}

AllCoCK, E. R., Reid, S. J., Jones, D. T. \& Woods, D. R. (1982). Clostridium acetobutylicum protoplast formation and regeneration. Applied and Environmental Microbiology 43, 719-721.

De Castro-Costa, M. R. \& Landman, O. E. (1977). Inhibitory protein controls the reversion of protoplasts and $\mathbf{L}$ forms of Bacillus subtilis to the walled state. Journal of Bacteriology 129, 678-689.

Ginsburg, I. \& SElA, M. N. (1976). The role of leukocytes and their hydrolases in the persistence, degradation, and transport of bacterial constituents in tissues: relation to chronic inflammatory processes in staphylococcal, streptococcal, and mycobacterial infections and in chronic periodontal diseases. Critical Reviews in Microbiology 4, 249-332.

HeefNer, D. L., Squires, C. H., Evans, R. J., Kopp, B. J. \& YARUS, M. J. (1984). Transformation of Clostridium perfringens. Journal of Bacteriology 159, 460-464.

HONGO, M. (1960). US patent no. 2945786.

Hongo, M., Tahara, Y. \& Ogata, S. (1974). Purification and properties of phage HM7-induced lytic enzyme of Clostridium saccharoperbutylacetonicum. Agricultural and Biological Chemistry 38, 755-761.

JONES, D. T., JoNES, W. A. \& Woods, D. R. (1985). Production of recombinants after protoplast fusion in Clostridium acetobutylicum P262. Journal of General Microbiology 131, 1213-1216.

LIN, Y. L. \& BLASCHEK, H. P. (1984). Transformation of heat-treated Clostridium acetobutylicum protoplasts with pUB 110 plasmid DNA. Applied and Environmental Microbiology 48, 737-742.

Minton, N. P. \& Morris, J. G. (1983). Regeneration of protoplasts of Clostridium pasteurianum ATCC 6013. Journal of Bacteriology 155, 432-434.
Ogata, S. \& Hongo, M. (1973). Bacterial lysis of Clostridium species I. Lysis of Clostridium species by univalent cation. Journal of General and Applied Microbiology 19, 251-261.

Ogata, S., Tahara, Y. \& Hongo, M. (1974). Mode of action of Clostridium saccharoperbutylacetonicum cell wall peptidoglycan. Agricultural and Biological Chemistry 38, 736-768.

Ogata, S., Chol, K. H. \& Hongo, M. (1975). Sucroseinduced autolysis and development of protoplastlike cells of Clostridium saccharoperbutylacetonicum. Agricultural and Biological Chemistry 39, 1247-1254.

SMITH, M. D. (1985). Transformation and fusion of Streptococcus faecalis protoplasts. Journal of Bacteriology 162, 92-97.

Stal, M. H. \& BlascheK H. P. (1985). Protoplast formation and cell wall regeneration in Clostridium perfringens. Applied Environmental Microbiology 50, 1097-1099.

Wecke, J., Lahav, M., Ginsburg, I., Kwa, E. \& GIESBRECHT, P. (1986). Inhibition of wall autolysis of staphylococci by sodium polyanethole sulfonate "liquoid". Archives of Microbiology 144, 110-115.

WIRTH, R., AN, F. Y. \& CLEWELL, D. B. (1986). Highly efficient protoplast transformation system for Streptococcus faecalis and a new Escherichia coli-S. faecalis shuttle vector. Journal of Bacteriology 165, 831-836.

Yoshino, S., Ogata, S. \& Hayashida, S. (1982). Some properties of autolysin of Clostridium saccharoperbutylacetonicum. Agricultural and Biological Chemistry 46, 1243-1248.

Yoshino, S., Ogata, S. \& Hayashida, S. (1984). Regeneration of protoplasts of Clostridium saccharoperbutylacetonicum. Agricultural and Biological Chemistry 48, 249-250. 